\title{
Fingerprint and weathering characteristics of crude oils after Dalian oil spill, China
}

\author{
Chuanyuan Wang ${ }^{\mathrm{a}, *}$, Bing Chen ${ }^{\mathrm{b}}$, Baiyu Zhang ${ }^{\mathrm{b}}$, Shijie He ${ }^{\mathrm{c}}$, Mingming Zhao ${ }^{\mathrm{a}}$

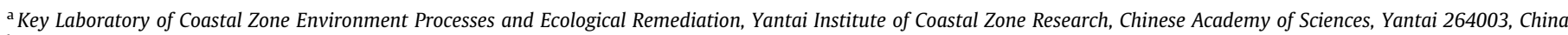 \\ ${ }^{\mathrm{b}}$ Faculty of Engineering \& Applied Science, Memorial University of Newfoundland, St. John's, NL A1B 3X5, Canada

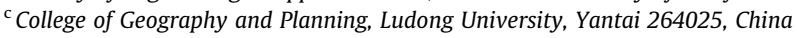

\section{A R T I C L E I N F O}

\section{Keywords:}

Source identification

Natural weathering

Diagnostic ratios

$\delta^{13} \mathrm{C}$

Dalian oil spill

\begin{abstract}
A B S T R A C T
In an attempt to analyze the chemical characterization of oil residues and examine the suitability of chemical fingerprinting methods in oil spill investigations, multiple parameters sensitive to both sources and degree of weathering were used to characterize oil residues from "7-16" Dalian oil spill, China. Oil residues collected 90 days to 120 days after the spill showed a weathering pattern where significant amounts of light to middle molecular weight normal alkanes were depleted with pristane and phytane as dominant peaks. Diagnostic ratios developed from $n$-alkane and selected isoprenoids (e.g. $\mathrm{Pr} / \mathrm{Ph}, n$ $\mathrm{C}_{17} / \mathrm{Pr}, n-\mathrm{C}_{18} / \mathrm{Ph}$, carbon preference index, LMW/HMW-alkanes ratio), all display obvious changes over weathering time, indicating that these ratios are not valid for oil source identification. Furthermore, the biomarker ratios of hopanes and steranes with relative standard deviations (RSDs) of $0.88-4.08 \%$ were useful for source identification even for severely weathered oil residues. In addition, RSD of $\delta^{13} \mathrm{C}$ values of individual $n$-alkanes in oil residue varied from $0.07 \%$ to $0.20 \%$, which suggest that stable carbon isotope profile of $n$-alkanes can also be a useful tool for tracing the source of an oil spill.
\end{abstract}

(C) 2013 Elsevier Ltd. All rights reserved.

\section{Introduction}

The worldwide extraction, transportation, and use of petroleum inevitably results in its release to the environment. Therefore the coastal zone ecosystem is threatened due to the potential events such as tanker accidents, well explosions or pipeline leaks. Oil spills cause extensive damage to marine and terrestrial life, human health, and natural resources. On July 16, 2010, in the northeastern port city of Dalian, a coastal city in northeast China's Liaoning Province, two oil pipelines exploded, sent flames hundreds of feet into the air and burnt for over $15 \mathrm{~h}$. The damaged pipes released thousands of barrels of oil, which flowed into the nearby harbor and the Yellow Sea. The total amount of oil spilled is about 1500 tons and the oil spread over $165 \mathrm{~km}^{2}$.

Once oil spilled into marine environment, it is subjected to a variety of weathering processes, including evaporation, dissolution, dispersion, flushing due to wave energy, emulsification, photochemical oxidation, microbial biodegradation, and adsorption to suspended matter and deposition on to the seafloor (Wang et al., 1997; Garrett et al., 1998; Ezra et al., 2000; D’Auria et al., 2009). Weathering processes may cause significant changes in the chemical composition of the spilled oil. The study on the chemical composition of oil spill cannot only be used to monitor the fate and behavior of the spilled oil in the marine environment, but also to refine the diagnostic values of the source recognition indices

\footnotetext{
* Corresponding author. Tel.: +86 5352109152.

E-mail address: cywang@yic.ac.cn (C. Wang).
}

(Wang et al., 1998; Yim et al., 2011; Wang et al., 2011). The combined effects of weathering can strongly modify the fingerprints and some common parameters used to correlate oil with its source on the basis of gas chromatography (GC) and gas chromatographymass spectrometry (GC-MS) analysis. Thus, the identification of spilled oil based on the basis of GC and GC-MS analysis becomes increasingly difficult with the lapse of time due to weathering processes. Stable carbon isotopic compositions of individual hydrocarbons in spilled oils and sediments may provide additional evidence that helps to trace oil spill sources (Mansuy et al., 1997; Mazeas and Budzinski, 2002; Wang and Fingas, 2003). The weathering processes under natural conditions are complicated and depend on a variety of factors such as the quantity and type of oil, the prevailing weather and sea conditions. Therefore, studies of weathering under natural conditions are essential for the understanding of these processes in the natural environment (Ezra et al., 2000; Prince et al., 2002; Braddock et al., 2003).

The Dalian oil spill provided an excellent opportunity to monitor the variation in the chemical composition of the spilled residual oil over time and characterize the weathering processes in the coastline of Dalian Bay under natural conditions. The oil spill has also given a better base for the source identification of oil spills using compound-specific carbon isotope analysis. The study focuses on three main aspects: (I) Weathered regulation of oil spilled in actual environment; (II) examining the suitability of chemical fingerprinting methods in oil spill investigations; (III) determination of the effects of natural weathering processes on the isotopic composition of individual $n$-alkanes and the evaluation of possibilities of GC-IRMS 
as a correlation tool in oil spill identification. To achieve these objectives, saturated hydrocarbons including alkanes and selected isoprenoids, biomarker compounds and the $\delta^{13} \mathrm{C}$ values of the $n$-alkane were quantitatively determined. In addition, a variety of diagnostic ratios were developed and evaluated for spill source identification and differentiation.

\section{Experiments}

\subsection{Sample collection for oil spill in Dalian}

The Dalian oil spill had been successfully controlled, 10 days after a pipeline blast leaked 1500 tons of heavy crude into the sea. Although large quantities of the pollutant have been successfully recovered, some oil residue attached to the rocks in Jinshatan was still found in the most affected area. A series of weathered oil residue in coastal zone from the Jinshitan were collected 10 days (DL- 1 ), 30 days (DL-2), 60 days (DL-3), 90 days (DL-4) and 120 days (DL-5) after the oil spill occurred. In addition, a fresh crude oil sample (DL-0) was collected from the oil tank. Oil samples were carefully taken and placed in prewashed amber glass bottles using a solvent washed spatula and stored at about $2{ }^{\circ} \mathrm{C}$ in the freezer until analysis within a week.

\subsection{Extraction, fractionation and GC-MS}

In the laboratory, oil samples were Soxhlet-extracted with chloroform for a period of $72 \mathrm{~h}$. The procedure used for separation and quantitation of individual alkanes and PAHs have been described elsewhere (Barakat et al., 2001; Duan et al., 2003). Briefly, an aliquot (50-100 mg) of the oil sample was dissolved in $20 \mathrm{ml} \mathrm{n}$-alkane and spiked with $100-500 \mathrm{ml}$ of hexane solutions of the deuterated alkane. The elemental sulfur was removed from the extracts using activated copper. The oil samples were deasphalted by precipitation with $n$-hexane followed by filtration. The extract was fractionated into aliphatic and aromatic hydrocarbons by adsorption liquid chromatography using a column of alumina and silica-gel, and gradient solvents as eluent:ligarine and ligarine/ dichloromethane $(3: 9, \mathrm{v} / \mathrm{v})$, respectively. The aliphatics was concentrated again on a rotary evaporator, transferred to a vial, and then the volume was adjusted to $1 \mathrm{ml}$ exactly using a stream of filtered $\mathrm{N}_{2}$ gas. An aliquot of $1 \mathrm{ml}$ of each extract was subjected to analysis. The saturated hydrocarbon fractions were distilled with $n$-hexane, and then analyzed by GC-MS. Straight chain hydrocarbons were separated from branched and cyclic hydrocarbons by treating the saturated fractions with $5 \mathrm{~A}$ molecular sieve using the procedure described by Duan et al. (2003) and Grice et al. (2008). The purified $n$-alkane fractions were determined by Gas chromatography-isotope ratio mass spectrometry (GC-IRMS).

The saturated hydrocarbons were analyzed with a 6890N GC$5973 \mathrm{~N}$ mass spectrometer. Sample extracts were injected in a splitless mode onto a HP- 5 capillary column $(50 \mathrm{~m} \times 0.32 \mathrm{~mm} \times 0.25 \mu \mathrm{m}$, Agilent Technologies, USA) at an initial temperature of $80^{\circ} \mathrm{C}$. The GC oven temperature was programmed to $300{ }^{\circ} \mathrm{C}$ at $4{ }^{\circ} \mathrm{C} \mathrm{min}^{-1}$ and was held at the final temperature for $30 \mathrm{~min}$. Helium was used as a carrier gas. Mass spectrometer conditions were electron ionization at $70 \mathrm{eV}$ with an ion source temperature at $250^{\circ} \mathrm{C}$.

Individual $n$-alkanes were identified based on the retention time of the authentic standards $\left(n \mathrm{C}_{10-40}\right.$, Sigma), and concentrations of each $n$-alkane were calculated based on the standard calibration curve of each corresponding standard compound. Biomarker ratios were calculated using peak areas from the $\mathrm{m} /$ $z=191$ and 217 chromatograms.

\subsection{GC-IRMS}

GC-IRMS analyses were performed on a VG Isoprime instrument (GV Instruments Ltd., UK). The GC was equipped with a HP-5 capillary column $(50 \mathrm{~m} \times 0.32 \mathrm{~mm} \times 0.25 \mu \mathrm{m})$ with helium as the carrier gas. The GC was held for $5 \mathrm{~min}$ at $70^{\circ} \mathrm{C}$, programmed to sequentially step from $70^{\circ} \mathrm{C}$ to $290{ }^{\circ} \mathrm{C}$ at $3{ }^{\circ} \mathrm{C} \mathrm{min}{ }^{-1}$, and then held for $40 \mathrm{~min}$ at $290^{\circ} \mathrm{C}$. The combustion furnace was run at $880^{\circ} \mathrm{C}$. Carbon isotope ratios for individual alkanes were calculated using $\mathrm{CO}_{2}$ as a reference gas that was automatically introduced into the IRMS at the beginning and end of each analysis, and the data was reported in per mil (\%o) relative to the Vienna Pee Dee Belemnite (VPDB) standard. A standard mixture of $n$-alkanes $\left(n-C_{12}-n-C_{32}\right)$ with known isotopic composition was used daily to test the performance of the instrument. Replicate analyses of this mixture show that the standard deviation for each compound is less than $0.3 \%$.

\section{Results and discussion}

\subsection{Alkane fingerprints}

\subsubsection{Alkane distribution}

Evaporation and emulsification occur in the first few hours after a spill and removes the more volatile hydrocarbons, and waterwashing also occurs rapidly and removes the more water-soluble hydrocarbons, typically hydrocarbons below $\mathrm{C}_{15}$ (Mansuy et al., 1997). At the same time, biodegradation will also start to affect the nature of the spilled oil by initially removing the $n$-alkanes before attacking the more complex branched and cyclic hydrocarbons and naphthenic compounds. A decrease in the overall concentrations of $n$-alkanes and isoprenoids indicated some loss of $50 \%$ in the spilled oil (Fig. 1). Within 120 days, these compounds were degraded largely and as a consequence, are of limited value in identifying the remaining oil residues.

The $n$-alkane envelope in the initial oil from the oil container is characterized by $n$-alkanes ranging from $C_{9}$ to $C_{36}$ and maximizing at $n-C_{15}$ and $n-C_{31}$ (Fig. 2a). Subsequently, there is an absence of aliphatic compounds $<n-C_{11}$ after 10 days and aliphatic compounds $<n-C_{13} 120$ days after the spill (Fig. 2-b). Based on this observation, the low-molecular-weight alkanes (LMW alkanes) $\left(n-C_{12}-n-C_{21}\right)$

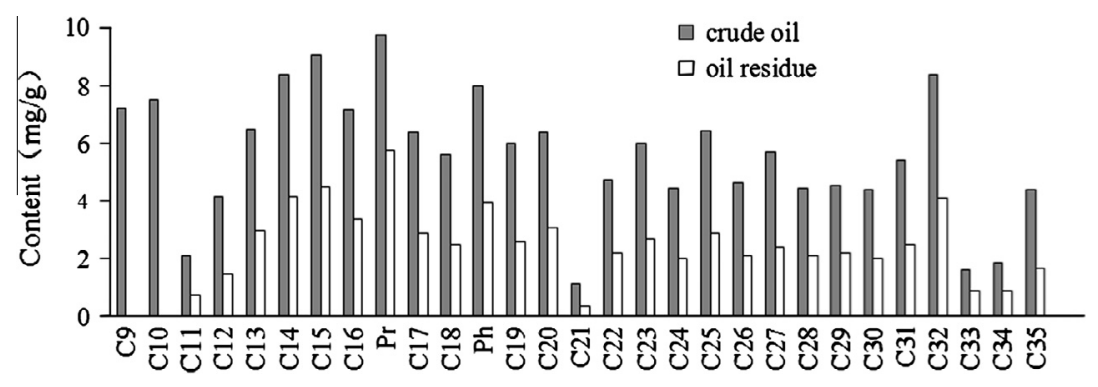

Fig. 1. Content of various alkane, pristane and phytane. 


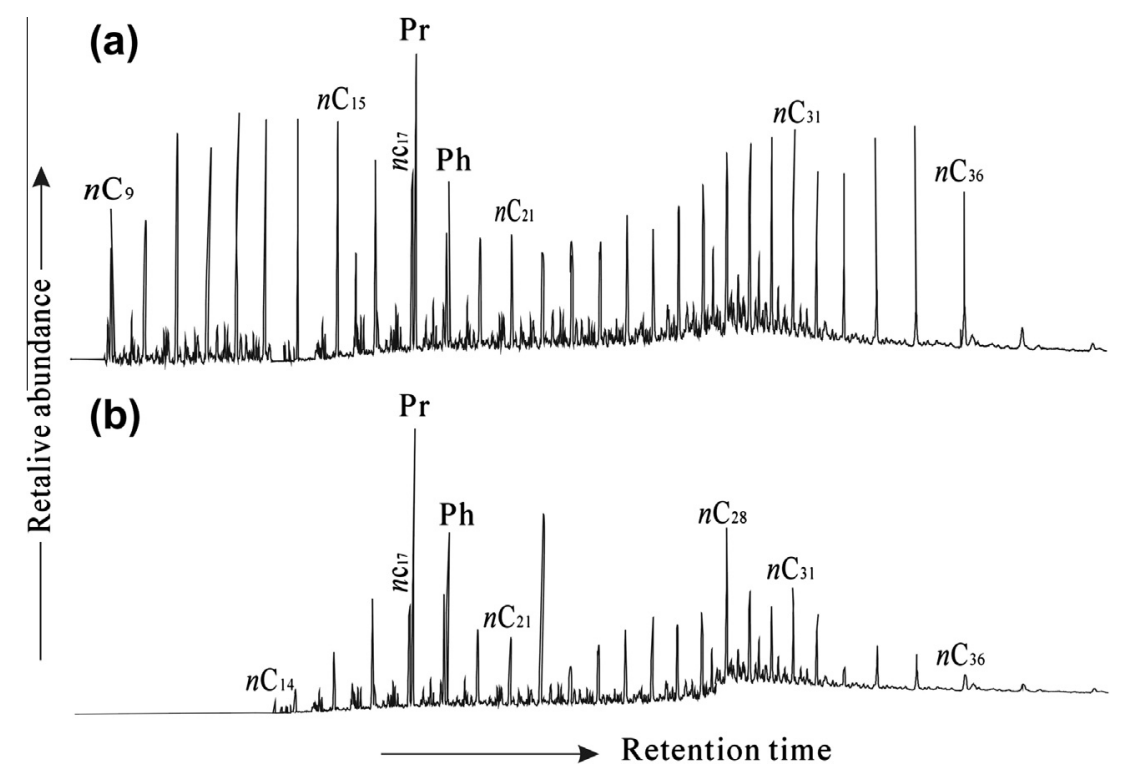

Fig. 2. Gas chromatograms of aliphatic hydrocarbons from initial oils (a) and oil residue 120 days after the spill (b).

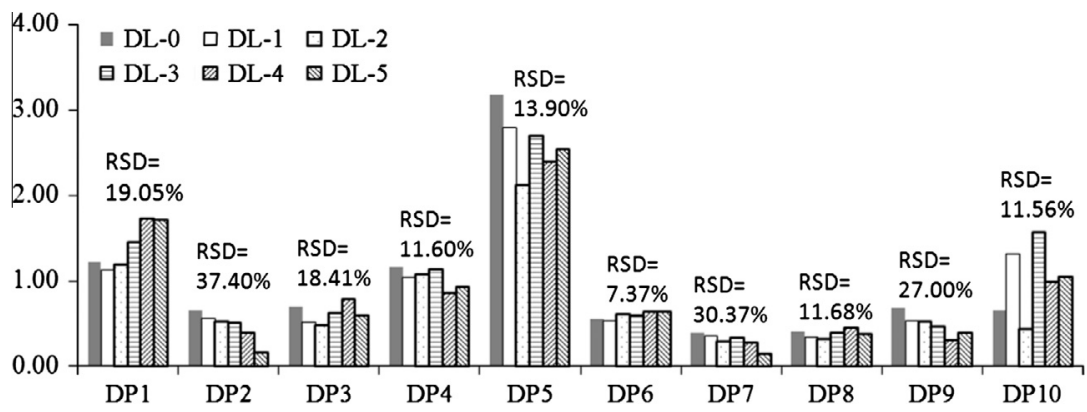

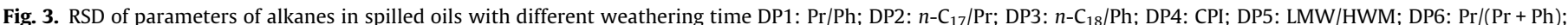

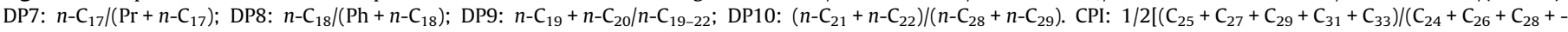
$\left.\left.{ }_{24}+C_{26}+C_{28}+C_{30}+C_{32}\right)+\left(C_{25}+C_{27}+C_{29}+C_{31}+C_{33}\right) /\left(C_{26}+C_{28}+C_{30}+C_{32}+C_{34}\right)\right]$; LMW/HWM: $n-C_{9}$ to $n-C_{21}$ alkanes relative to the sum of $n-C_{22}$ to n- $C_{34}$ alkanes.

may have undergone microbial degradation compared to the highmolecular-weight alkanes (HMW alkanes) $\left(n-C_{22}-n-C_{36}\right)$. The weathered oils exhibit a substantially lower value of the LMW/ HMW-alkanes ratio $\left(\sum n-C_{11}-n-C_{21} / \sum n-C_{22}-n-C_{36}, 2.53\right)$ compared to the initial oils (3.18).

The $n$-alkanes are progressively depleted in oil samples with increasing extent of weathering. $n-\mathrm{C}_{17} /$ pristane $\left(n-\mathrm{C}_{17} / \mathrm{Pr}\right)$ and $n$ $\mathrm{C}_{18} /$ phytane $\left(n-\mathrm{C}_{18} / \mathrm{Ph}\right)$ indices have been widely used as indicators of oil biodegradation (Kennicutt, 1988; Barakat et al., 2001; Wang and Fingas, 2003). As the easily degraded normal hydrocarbons ( $n$ $\mathrm{C}_{17}$ and $n-\mathrm{C}_{18}$ ) are lost, the more degradation resistant isoprenoids (pristane and phytane) are conserved (Barakat et al., 2002; Wang and Fingas, 2003), resulting in a significant decrease of the ratios of $n-\mathrm{C}_{17} / \mathrm{Pr}$ and $n-\mathrm{C}_{18} / \mathrm{Ph}$ in the weathered oil residues samples (Fig. 3).

PAHs are relatively stable and may provide more detailed compound specific data that can be used to identify both source and degradation extent (Douglas et al., 1996). Short-term weathering generally does not affect diagnostic ratios of target PAHs, thus, the fingerprint and weathering characteristics of polycyclic aromatic hydrocarbons (PAHs) will not be discussed in this study.

\subsubsection{Evaluation on the diagnostic ratios of alkane for the} identification of spilled oils

Parameters generated from $n$-alkane and isoprenoid distributions have a tendency to change under the influence of weathering process. Based on the evaluation method of indices suggested by Stout et al. (2001) and Li et al. (2009), relative standard deviation (\%RSD) is considered as an indicator to evaluate the variability of diagnostic indices in this experiment. The indices with \%RSD <5\% are probably not affected by weathering, while a \%RSD more than $5 \%$ suggests that weathering has a remarkable effect on the index. For the weaker weathering oil after 30 days, except the ratios of $\mathrm{Pr} /$ $\mathrm{Ph}$ and carbon preference index (CPI), other ratios of $n-\mathrm{C}_{17} / \mathrm{Pr}, n$ $\mathrm{C}_{18} / \mathrm{Ph}, \mathrm{Pr} /(\mathrm{Pr}+\mathrm{Ph}), n-\mathrm{C}_{17} /\left(\mathrm{Pr}+n-\mathrm{C}_{17}\right), \quad n-\mathrm{C}_{18} /\left(\mathrm{Ph}+n-\mathrm{C}_{18}\right), \quad \mathrm{LMW} /$ HWM, $\left(n-\mathrm{C}_{21}+n-\mathrm{C}_{22}\right) /\left(n-\mathrm{C}_{28}+n-\mathrm{C}_{29}\right)$ and $n-\mathrm{C}_{19}+n-\mathrm{C}_{20} / n-\mathrm{C}_{19-22}$ all display obvious changes over weathering time, indicating that these ratios are not valid for oil source identification. Moreover, all the ratios display obvious changes over weathering time (Fig. 3), especially for $\mathrm{Pr} / n-\mathrm{C}_{17}, \mathrm{Ph} / n-\mathrm{C}_{18}$ with a RSD of more than $43.68 \%$, indicating that these ratios are not valid for oil source identification of the spill moderately degraded. Similar features were reported by Barakat et al. (2002) and Wang and Fingas (2003) for the degraded oil spill.

\subsection{Characterization of biomarker compounds}

Terpanes and steranes are common biomarkers in oil correlation, source identification, and maturity determination (Duan et al., 2003). Unlike the aliphatic distributions, hopane and sterane distributions obtained for the residual oil and initial samples analyzed in this study were similar. For example, the distribution 


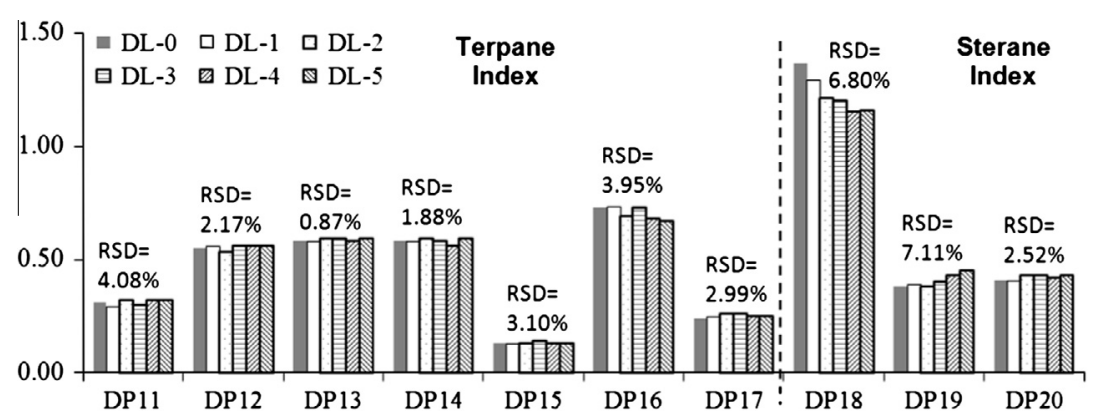

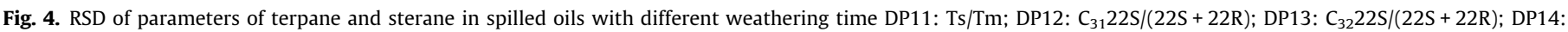

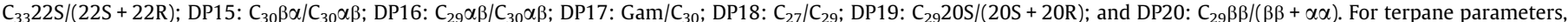

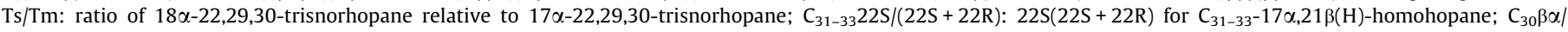

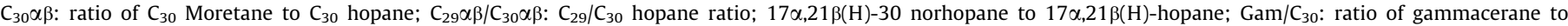

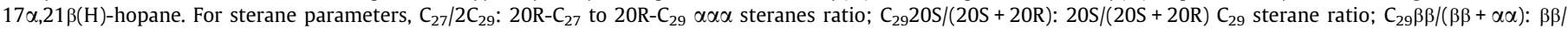
$(\beta \beta+\alpha \alpha) C_{29}$ sterane ratio.

profiles of terpanes in such oils are all dominated by hopanes comprised of $C_{27}-C_{35}$ members, with the $17 \alpha, 21 \beta(H)$-hopane isomers being the major compounds. In addition, the initial oils contain $\mathrm{C}_{27}-\mathrm{C}_{30}$ steranes dominated by $5 \alpha(\mathrm{H}), 14 \alpha(\mathrm{H}), 17 \alpha(\mathrm{H})$ components, with the $20 \mathrm{R}$ isomers more abundant than the $20 \mathrm{~S}$ isomers.

In this paper, the traditional indicators for the biomarkers, widely used in petroleum exploration, source identifiers and weathering assessment tools, are considered (Fig. 4). As expected, all indices of terpane and sterane have lower standard deviations and \%RSD ( $<5 \%)$, displaying little change after degradation. The results are also similar to those previous reports, which showed that terpane and sterane are more resistant to degradation than alkanes, isoprenoids (Wang et al., 2001; Barakat et al., 2002). As mentioned above, terpanes and steranes retained their molecular compositions during 120 days weathering process under natural marine environment. Thus, such diagnostic ratios from terpanes and steranes compounds could be used in tracking the origin and sources of hydrocarbon pollution in the marine environment.

\subsection{Effect of weathering on the carbon isotopic composition of the n- alkanes}

GC-IRMS is a powerful tool for identifying the source of organic matter (Freeman et al., 1990; Hayes et al., 1990) and correlating oil with possible source rocks (Bjorøy et al., 1994) in petroleum geochemistry. The carbon isotope ratio of crude oil is inherited from the source organic matter, but is influenced by maturity and by physical and chemical alteration after generation (Xu et al., 2001; Duan et al., 2003; Philp, 2007). For example, LMW alkanes may reflect algal or bacterial contributions while HMW alkanes may originate in plant waxes or from degradation of complex algal and plant molecules. Thus, stable carbon isotopic compositions of individual hydrocarbons in spilled oils and sediments may provide additional evidence that helps to trace oil spill sources (Mansuy et al., 1997; Mazeas and Budzinski, 2002). So, it is very important to understand the relationship between the weathering processes and the isotopic composition of individual $n$-alkanes. Previous study has indicated that short-term weathering has no significantly effect on the $\delta^{13} \mathrm{C}$ values of $n$-alkane (Li et al., 2009). However, little work has been done about evaluation of the effect of moderately weathered on the carbon isotopic distribution of $n$-alkane for oil spill identification under natural marine environment based on a typical oil spill accident.

For the oil sample from Dalian Bay, the $\delta^{13} \mathrm{C}$ values for the $n$-alkanes, pristane and phytane did not vary according to any readily identifiable trend (Fig. 5). The standard deviations of $\delta^{13} \mathrm{C}$ values of individual n-alkanes varied from $0.07 \%$ to $0.20 \%$ for Dl- 0 and DL-3 ( 60 days), and ranged $0.06 \%$ to $0.36 \%$ for samples Dl-0 and DL-4 (90 days). Even for the longer weathering samples (DL-5) over 120 days, the standard deviations of $\delta^{13} \mathrm{C}$ values of individual $n$-alkanes varied from $0.07 \%$ to $0.20 \%$, which showed that the weathering has no significant effect on values of individual $n$-alkanes. In agreement with previous report (Mansuy et al., 1997; Hough et al., 2006; Li et al., 2009), stable carbon isotopic compositions of $n$-alkanes show no significant change during the entire course of weathering.

As discussed in Section 3.1, marked differences in chemical composition are present between weathered and unweathered

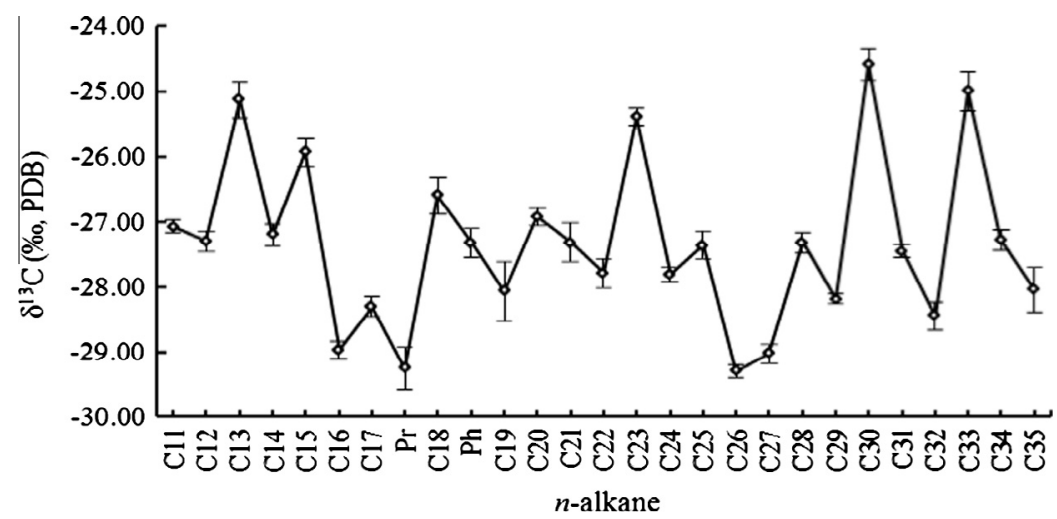

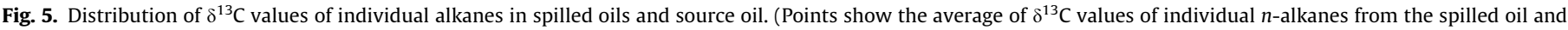
the source oil. Short line represents standard deviation of $\delta^{13} \mathrm{C}$ values for each individual compound). 
oils, hindering the comparison of spilled oils with their suspected oil sources. In contrast, weathering has no obvious effect on $\delta^{13} \mathrm{C}$ values of individual $n$-alkanes, suggesting that carbon isotopic profile of $n$-alkanes can be used as a powerful tool for identifying the source of oil spills.

\section{Conclusions}

Dalian oil spill in 2010 provided an excellent opportunity to monitor the variation in the chemical composition of the spilled residual oil over time and characterize the weathering processes in the coastline of Dalian Bay under natural marine conditions. Oil residues collected $90-120$ days after the spill showed a weathering pattern where significant amounts of light to middle molecular weight normal alkanes were depleted with pristane and phytane as dominant peaks. Diagnostic ratios developed from $n$-alkane and selected isoprenoids, such as $\mathrm{Pr} / \mathrm{Ph}, n-\mathrm{C}_{17} / \mathrm{Pr}, n-\mathrm{C}_{18} / \mathrm{Ph}$, CPI, LMW/HWM, $\operatorname{Pr} /(\mathrm{Pr}+\mathrm{Ph}), \quad n-\mathrm{C}_{17} /\left(\mathrm{Pr}+n-\mathrm{C}_{17}\right), \quad n-\mathrm{C}_{18} /(\mathrm{Ph}+n-$ $\left.C_{18}\right), n-C_{19}+n-C_{20} / n-C_{19-22}$ and $\left(n-C_{21}+n-C_{22}\right) /\left(n-C_{28}+n-C_{29}\right)$ all display obvious changes ( $R S D=7.37-41.56 \%$ ) over weathering time, indicating that these ratios are not valid for oil source identification. The data confirmed previous observations that $\mathrm{Ts} / \mathrm{Tm}$, $\mathrm{C}_{312} 2 \mathrm{~S} /(22 \mathrm{~S}+22 \mathrm{R}), \quad \mathrm{C}_{32} 22 \mathrm{~S} /(22 \mathrm{~S}+22 \mathrm{R}), \quad \mathrm{C}_{33} 22 \mathrm{~S} /(22 \mathrm{~S}+22 \mathrm{R})$, $C_{30} \beta \alpha / C_{30} \alpha \beta, C_{29} \alpha \beta / C_{30} \alpha \beta, G a m / C_{30}, C_{27} / C_{29}, C_{29} 20 S /(20 S+20 R)$, $C_{29} \beta \beta /(\beta \beta+\alpha \alpha)$ were nearly constant in oil residues, and to be most suitable for the source identification and correlation.

The oil spill in Dalian has also given a better base for the source identification of oil spills using compound-specific carbon isotope analysis. For Dalian oil spill, the standard deviations of $\delta^{13} \mathrm{C}$ values of individual $n$-alkanes varied from $0.07 \%$ to $0.20 \%$, which showed that the weathering has no significant effect on values of individual $n$-alkanes over 120 days natural weathering. The alkanes still show almost identical $\delta^{13} \mathrm{C}$ values to that of the unaltered sample for such the moderate biodegradation sample. Therefore, the isotopic profile of $n$-alkanes can certainly be used to identify the source of an oil spill, especially for those oils mainly consisting of $\mathrm{C}_{10^{-}}$ $\mathrm{C}_{20}$ n-alkanes with low concentrations of biomarkers.

\section{Acknowledgements}

This work was financially supported by National Natural Science Foundation of China (Grant No. 40806048), Key Projects in the Yantai Science \& Technology Pillar Program (2011060) and the Key Laboratory for Ecological Environment in Coastal Areas, State Oceanic Administration (200907).

\section{References}

Barakat, A.O., Mostafa, A.R., Qian, Y., Kennicutt II, M.C., 2002. Application of petroleum hydrocarbon chemical fingerprinting in oil spill investigations-Gulf of Suez. Egypt. Spill Sci. Tech. Bull. 7, 229-239.

Barakat, A.O., Qian, Y., Kim, M., Kennicutt, M.C., 2001. Chemical characterization of naturally weathered oil residue in arid terrestrial environmental in Al-Alamein. Egypt Environ. Sci. Technol. 27, 291-310.
Bjorøy, M., Hall, K., Moe, R.P., 1994. Stable carbon isotope variations of n-alkanes in Central Graben oils. Org. Geochem. 22, 355-381.

Braddock, J.F., Lindstrom, J.E., Prince, R.C., 2003. Weathering of a subarctic oil spill over 25 years: the Caribou-Poker Creeks Research Watershed experiment. Cold Reg. Sci. Technol. 16, 11-23.

D’Auria, M., Emanuele, L., Racioppi, R., Velluzzi, V., 2009. Photochemical degradation of crude oil: comparison between direct irradiation, photocatalysis, and photocatalysis on zeolite. J. Hazard. Mater. 164, 32-38.

Douglas, G.S., Bence, A.E., Prince, R.C., Mcmillen, S.J., Butler, E.L., 1996. Environmental stability of selected petroleum hydrocarbon source and weathering ratios. Environ. Sci. Technol. 30, 2332-2339.

Duan, Y., Zhang, H., Wu, B.X., Zheng, Z.Y., 2003. Carbon isotopic studies of individual n-alkanes in crude oils from Qaidam Basin. J. Mineral. Petrol. 23, 91-94.

Ezra, S., Feinstein, S., Pelly, I., Bauman, D., Miloslavsky, I., 2000. Weathering of fuel oil spill on the east Mediterranean coast, Ashdod. Israel Org. Geochem. 31, 1733-1741.

Freeman, K.H., Hayes, J.M., Trendel, J.M., Albrecht, P., 1990. Evidence from carbon isotope measurements from diverse origins of sedimentary hydrocarbons. Nature 343, 254-256.

Garrett, R.M., Pickering, I.J., Haith, C.E., Prince, R.C., 1998. Photooxidation of crude oils. Environ. Sci. Technol. 32, 3719-3723.

Grice, K., Mesmay, R., Glucina, A., Wang, S., 2008. An improved and rapid 5A molecular sieve method for gas chromatography isotope ratio mass spectrometry of n-alkanes $\left(\mathrm{C}_{8-} \mathrm{C}_{30+}\right)$. Org. Geochem. 39, 284-288.

Hayes, J.M., Freeman, K.H., Popp, B.N., Hoham, C.H., 1990. Compound-specific isotopic analyses: a novel tool for reconstruction of ancient biochemical processes. Org. Geochem. 16, 1115-1128.

Hough, R.L., Whittaker, M., Fallick, A.E., Preston, T., Farmer, J.G., Pollard, S.J.T., 2006. Identifying source correlation parameters for hydrocarbon wastes using compound-specific isotope analysis. Environ. Pollut. 143, 489-498.

Kennicutt II, M.C., 1988. The effect of biodegradation on crude oil bulk and molecular composition. Oil. Chem. Pollut. 4, 89-112.

Li, Y., Xiong, Y.Q., Yang, W.Y., Xie, Y.L., Li, S.Y., Sun, Y.G., 2009. Compound-specific stable carbon isotopic composition of petroleum hydrocarbons as a tool for tracing the source of oil spills. Mar. Pollut. Bull. 58, 114-117.

Mansuy, I., Philp, R.P., Allen, J., 1997. Source identification of oil spills based on the isotopic composition of individual components in weathered oil samples. Environ. Sci. Technol. 31, 3417-3425.

Mazeas, L., Budzinski, H., 2002. Stable carbon isotopic study $\left({ }^{12} \mathrm{C} /{ }^{13} \mathrm{C}\right)$ of the fate of petrogenic PAHs (methyphenanthrenes) during an in situ oil spill simulation experiment. Org. Geochem. 33, 1253-1258.

Philp, R.P., 2007. The emergence of stable isotopes in environmental and forensic geochemistry studies: a review. Environ. Chem. Lett. 5, 57-66.

Prince, R.C., Owens, E.H., Sergy, G.A., 2002. Weathering of an Arctic oil spill over 20 years: the BIOS experiment revisited. Mar. Pollut. Bull. 44, 1236-1242.

Stout, S.A., Uhler, A.D., McCarthy, K.J., 2001. A strategy and methodology for defensibly correlating spilled oil to source candidates. Environ. Forensics 2, 8798.

Wang, Z.D., Fingas, M.F., 2003. Development of oil hydrocarbon fingerprinting and techniques. Mar. Pollt. Bull. 47, 423-452.

Wang, Z., Fingas, M., Landriault, M., Sigouin, L., Feng, Y., Mullin, J., 1997. Using systematic and comparative analytical data to identify the source of an unknown oil on contaminated birds. J. Chromatogr. A 775, 251-265.

Wang, Z.D., Fingas, M., Blenkinsopp, S., Sergy, G., Landriault, M., Sigouin, L., Foght, J., Semple, K., Westlake, D.W.S., 1998. Comparison of oil composition changes due to biodegradation and physical weathering in different oils. J. Chromatogr. A 809, 89-107.

Wang, Z.D., Fingas, M., Sigouin, L., 2001. Characterization and identification of a "mystery" oil spill from Quebec (1999). J. Chromatogr. A 909, 155-169.

Wang, C.Y., Du, J.G., Gao, X.L., Duan, Y., Sheng, Y.Q., 2011. Chemical characterization of naturally weathered oil residues in the sediment from Yellow River Delta. China Mar. Pollt. Bull. 62, 2469-2475.

Xu, Y.C., Shen, P., Liu, W.H., Guan, P., Huang, D.F., 2001. Isotopic composition characteristics and identification of immature and low-mature oils. China Sci. Bull. 46, 1923-1929.

Yim, U.H., Ha, S.Y., An, J.G., Won, J.H., Han, J.M., Hong, S.H., Kim, M., Jung, J.H., Shim, W.J., 2011. Fingerprint and weathering characteristics of stranded oils after the Hebei Spirit oil spill. J. Hazard. Mater. 197, 60-69. 